\title{
Census of Non-Western Near-Death Experiences to 2005: Overview of the Current Data
}

\author{
Allan Kellehear, Ph.D. \\ Department of Social and Policy Sciences, \\ University of Bath, UK
}

ABSTRACT: This paper provides a census of non-Western near-death experiences (NDEs), noting similarities and differences in features with Western NDEs and other non-Western NDEs. The two aims of this current review are to update previous transcultural reviews with current data and to describe both crosscultural and culture-specific features of NDEs.

KEY WORDS: culture; national differences; non-Western; social experiences.

This is an overview and transcultural assessment of all published non-Western cases of near-death experience (NDE) in the current literature. The current review represents the third census of this kind that I have attempted. The first survey appeared in the Journal of Nervous and Mental Disease (Kellehear, 1993) with a later version appearing in my book Experiences Near Death (Kellehear, 1996). I offer here an update of these earlier surveys integrating the published cultural data that have appeared in the literature in the last 10 years since my earlier work but also including some earlier overlooked work. A critical discussion of the theoretical and methodological limitations of these data may be found in a broader essay currently in press (Kellehear, in press).

Allan Kellehear, Ph.D., is Professor of Sociology and Head of the Department of Social and Policy Sciences at the University of Bath. Reprint requests should be addressed to Professor Kellehear at the Department of Social and Policy Sciences, University of Bath, Bath BA2 7AY, United Kingdom; e-mail: a.kellehear@bath.ac.uk. 
I review here only the NDE phenomenology associated with illness. There are two reasons for this restriction. First, these circumstances are the main ones clinicians are likely to encounter. Second, these circumstances are the main ones associated with the NDE in the popular and academic imagination. This is also a good starting point to show that culture, rather than physical processes, seem to provide the critical influence in these experiences. Attempts to characterize NDE features such as the tunnel sensation or life review as "universal" experiences near death have led to idiosyncratic and premature theorizing from medical (Woerlee, 2004) and psychological researchers (Blackmore and Troscianko, 1989).

There is an important need to link the cultural, psychological, and physiological data to appreciate the interrelationship between the three experiential domains in generating a complete and balanced portrait of human experiences near death. In any pursuit of causal theory, whatever its limitations, it is also valuable to define one's hypotheses as accurately as possible and to know the specific limits and qualifications associated with that exercise in hypothesis generation and testing. Transcultural data are an essential moderating factor in the achievement of these scientific aims and this paper provides this specific contribution.

\section{Non-Western NDEs}

\section{China}

Contemporary accounts of Chinese NDEs in the academic literature are fragmentary and piecemeal. What we know about Chinese NDEs comes to us primarily through the historical work of Carl Becker (1981, 1984) and the more recent empirical work by Feng Zhi-ying and Liu JianXun (1992). Becker reviewed three traditional biographical accounts of well-known Chinese monks who were important to the founding of Pure Land Buddhism. Each monk experienced a serious illness that resulted in either an NDE or a deathbed vision while still reasonably conscious. In each of these accounts, no tunnel experience was reported, although one person proceeded "through a void" (Becker, 1984, p. 163). Neither the out-of-body experience (OBE) nor the life review was mentioned in these accounts. Encountering other beings, usually religious figures, and observing supernatural environs, usually interpreted as the paradisiacal "pure land," were consistent throughout the three narratives. 
In a later work, Becker (1984) provided a secondary analysis of the works of Saeko Ogasawara (1963) and Whalen Lai (1996). Ogasawara documented about 20 accounts of deathbed visions, and Lai documented up to 100 . Becker argued that the analysis of deathbed visions revealed features of the NDE that were strikingly parallel, an observation made earlier by Karlis Osis and Erlendur Haraldsson (1977). Once again, though, there was no report of a tunnel sensation. However, emerging from a "dark tubular "calyx" was reported (Becker, 1984, p. 64). There was no report of an OBE, but a life review was suggested by one person who saw all his "sinful deeds" (Becker, 1984, p. 64). Once again, supernatural environs and beings of light were witnessed.

Zhi-ying and Jian-xun conducted a recent study of Chinese NDEs (1992). They interviewed 81 survivors of the Tangshan earthquake of 1976 and found that 32 of them reported NDEs. Their survey suggested that most of the Western NDE phenomenology was also present in their sample. OBEs, tunnel sensations, sensations of peace, life reviews, meeting deceased beings, and sightings of an unearthly realm of existence were all reported in their study. Unfortunately, they did not include descriptive cases that we can analyze for content; thus, observations about their data cannot be scrutinized further. For example, although Zhi-ying and Jian-xun assert that "a tunnel-like dark region" was reported by their respondents, this was, in fact, a response to a prior descriptive category offered to them. Thus, we are unsure whether the tunnel sensation was a volunteered descriptor for this part of their experience.

Finally, an early survey some colleagues and I conducted in China (Kellehear, Heaven, and Gao, 1990) indicated that the Chinese experience and/or understanding of the NDE may not be very different from the Anglo-European one. Similar to Zhi-ying and Jian-xun, we presented a typical Anglo-European vignette of an NDE to a sample of 197 Chinese in Beijing. Twenty-six of these respondents claimed to have had an experience similar to the one described in that survey. Overall it seems that, from the historical and survey evidence available, the Chinese NDE may be very similar to the AngloEuropean NDE.

\section{India}

The first major report of NDEs from India came to us from the work of Osis and Haraldsson (1977), who interviewed 704 Indian medical 
personnel about their experiences with the dying. In this sample, there were 64 reports of NDEs. The remaining reports concerned neardeath visions. More recently and directly, Satwant Pasricha and Ian Stevenson (1986) reported sixteen cases of NDE from India. In the majority of cases (10) the respondents were actually interviewed by the authors, while in most of the others a "firsthand informant" was interviewed. In later studies by Pasricha $(1992,1993)$ another 29 cases of Indian NDE were uncovered.

In a total of 45 cases, then, Pasricha $(1992,1993)$ and Pasricha and Stevenson (1986) found no evidence of a tunnel sensation. There was one case report of an OBE. A life review was regularly reported, but this took the form of a reading by others of the record of the experiencer's life. The panoramic review commonly mentioned by Anglo-Europeans was not reported in this Indian sample. The reading of a person's record is a traditional Hindu belief that, according to the authors, is apparently widely held or known to the people of India. Finally, observing religious figures and deceased beings was part of these Indian NDE reports. These beings were observed in a supernatural world whose features resemble the traditional view of the "other realm."

The Indian NDE accounts collected by Pasricha and Stevenson (1986) did not seem to exhibit tunnel and OBE features. However, Osis and Haraldsson (1977), in their interviews with Indian health personnel, found several reports of OBEs in Indian patients near death. Susan Blackmore (1993) claimed to have found cases of tunnel sensations in Indian NDEs in her survey of eight respondents. However, on closer inspection, all three of those who supposedly reported tunnel sensations actually reported a sensation of darkness. One respondent agreed that her experience of darkness was "tunnellike" only after accepting this suggestion from Blackmore. This raises two important methodological problems (Kellehear, Stevenson, Pasricha, and Cook, 1994). First, the acceptance of one descriptor does not mean that the description offered was entirely satisfactory. Another, less geometric descriptor, such as an experience of twilight or night darkness, may also have been accepted, even preferred, if this were offered as a choice. Second, because Blackmore recruited her respondents through an advertisement in an English newspaper in India (rather than a Hindi newspaper), her respondents were not typical of people from India. We are therefore unable to draw any conclusion on this subject from Blackmore's study. 
A life review and observing a transcendent world in Indian NDEs have parallels with Anglo-European accounts. However, the figures observed in this world, deceased acquaintances aside for the moment, were those suggested by traditional Indian or Chinese mythology. Nevertheless, as Pasricha and Stevenson (1986) warned, social variations in another realm, if it exists, should be expected, just as they exist in our own world. The appearance of familiar cultural images may be psychological, but it may also be sociological and empirical. In other words, either projection may account for the visions, or the visions may actually be observations of another empirical world that resembles the world of its "expatriate" inhabitants.

\section{Thailand}

Ten reports of Thai NDEs have come to us from Todd Murphy (2001), who obtained these from published accounts while living in Thailand. Similar to accounts from China and India, the Thai NDEs were heavily influenced or stylized by Buddhist beliefs and ideas.

There was one report of an OBE, but Murphy argued that the appearance of Yamatoots, guides sent on behalf of the Lord of the Underworld (Yama), more often acted as evidence to the NDEr that he or she had died. There were no reports of tunnels or tunnel-like sensations, although a tunnel was reported as part of an otherworld journey. In that context, Murphy observed that "Tunnels are rare, if not absent, in Thai NDEs" (2001, p. 170).

Clearly there were encounters with supernatural beings, as evidenced first in the meeting with the Yamatoots and sometimes with the great Yama himself. Although Murphy stressed that there was no meeting with a "being of light," nevertheless Yama and or Yamatoots perform nearly all the same or similar roles that "beings of light" do for Westerners: guiding, supporting, or facilitating or accompanying a life review.

Life reviews were also present in these Thai accounts, but the culture-specific variation to note here is that the review was not panoramic, that is, not usually a review covering one's entire life or even a major slice of that life. Rather, the review examined one particular incident in the experiencer's life and the discussion was couched in terms of "merit" (boon) or sinful action (baap). Such terms relate to an overall view of Karma that, for many Thais, is somewhat 
simplified into the principle: "Do good; receive good. Do bad; receive bad" (Murphy, 2001, p. 168).

\section{Tibet}

Lee Bailey (2001) reported 16 NDEs drawn from accounts of Tibetan delogs, people who revived spontaneously from apparent death. These were ambiguous accounts for at least two reasons. First, it is not entirely clear that these were NDE accounts as we understand them in Western clinical terms, that is, genuinely mystical experiences emerging from critical illness or near-fatal accident. Some of the experiencers, for example, regularly had "dyings" on fasting days such as the " $10^{\text {th }}, 15^{\text {th }}$ and $30^{\text {th }}$ of each month" (Bailey, 2001, p. 143). Secondly, local observers of these NDErs and their "NDEs" seemed to view them as epileptics. People were thought to encounter the otherworld through their epileptic seizures or an encounter with the otherworld was evidenced by such seizures. Either way, these were not the usual ways that we would ordinarily view NDEs.

Notwithstanding these reservations, not all of the accounts displayed these background features. Some of the NDE accounts did seem to conform to a major period of illness; that is, they did not occur predictably or were not associated with epilepsy. For the sake of completeness then, and to avoid the risk of overlooking a potentially important cultural source of NDEs, I included these accounts. Bailey (2001) drew from $16 \mathrm{NDE}$ accounts derived from 12 written documents from the Tibetan Library of Works and Archives in Dharamsala, India, and 4 interview-based accounts from Françoise Pommaret (1989).

In all of these accounts there was no mention of a tunnel sensation, but there were accounts of OBEs, meeting supernatural beings, and experiencing a form of life review. These accounts were strikingly similar to those we have already seen from China, India, and Thailand, largely because of the influence of Buddhist beliefs and ideas on the supernatural beings and environments encountered.

\section{Guam}

Timothy Green (1984) reported four cases of NDEs among the Chammorro of Guam. Two of these cases involved direct interviews conducted by Green. The other two cases were collected by a local man who was interested in the subject of NDEs. 
Table 1

Summary of sources and cases on non-Western NDEs

\begin{tabular}{|c|c|c|}
\hline Culture & Cases & Sources \\
\hline \multicolumn{3}{|l|}{ Asia: } \\
\hline China & $100-180$ & $\begin{array}{l}\text { Becker, 1981, 1984; Zhi-ying and } \\
\text { Jian-xun, } 1992\end{array}$ \\
\hline India & 109 & $\begin{array}{c}\text { Osis and Haraldsson, 1977; Pasricha, 1992, } \\
\text { 1993; Pasricha and Stevenson, } 1987\end{array}$ \\
\hline Thailand & 10 & Murphy, 2001 \\
\hline Tibet & 16 & Bailey, 2001 \\
\hline \multicolumn{3}{|l|}{ Pacific Area: } \\
\hline Western New Britain & 3 & Counts, 1983 \\
\hline Hawaii & 1 & Kellehear, 2001 \\
\hline Guam & 4 & Green, 1984 \\
\hline Maori & 1 & King, 1985 \\
\hline \multicolumn{3}{|c|}{ Hunter-Gatherer Societies: } \\
\hline Native America & 14 & $\begin{array}{l}\text { Schorer, 1985-86; Gómez-Jeria, 1993; } \\
\text { Wade, } 2003\end{array}$ \\
\hline Africa & 15 & Morse and Perry, 1993 \\
\hline Aborigine & 1 & Berndt and Berndt, 1989 \\
\hline
\end{tabular}

Like the NDEs gathered in India and China, the Chammorro cases included visits to a paradisiacal place of gardenlike appearance. Here the NDEr was met by deceased beings, some of whom were relatives. Unlike the Indian and Chinese cases, however, OBEs were reported; the respondents recounted flying "through the clouds" and making invisible visits to living relatives in America. There was no mention of life review of any sort in these accounts or of any tunnel experience. Indeed, the transition from the ill and unconscious state to the OBE appearance was unexplained. Respondents suddenly found themselves flying through the sky or walking on a road. The emphasis of the narrative was on the social experiences while unconscious, that is, of meeting deceased relatives or experiencing a flying visit to living ones.

\section{Hawaii}

I reported one case (Kellehear, 2001) of an Hawaiian NDE identified from an old published source, Thomas Thrum's (1907) Hawaiian Folk 
Tales. One of these stories was a report of Kalima, a woman who "died" in Kona, Hawaii. She had been ill for weeks before appearing to die and only revived when she was placed alongside her soon-to-be grave for her funeral rites.

Kalima reported an OBE at the commencement of her remarkable account. But instead of then turning toward a light or tunnel, she reported simply that she turned and began walking out of her house and then her own village. She eventually came across another village with many people there, in fact, thousands of people. Her next surprise was that everyone she met whom she had once known were actually people who had previously died.

Kalima continued her walk, now apparently understanding that she was compelled to walk and was apparently heading unerringly toward Pele's Pit, a traditional volcano site for the jumping off of souls of the dead. However, before she was able to reach that point, she encountered a small group of people who informed her that it was not her time yet and that she had to return to her people in life. Reluctant to do this, she was driven back to her life by the crowds in this otherworld.

Once again, no tunnel was reported in this account. A life review was also absent in this report. However, if Kalima had leaped into the volcano, would that have been described as a tunnel-like experience? Even so, the journey through darkness came at a structurally different location in the NDE from where we are accustomed to viewing it - at the beginning - and this suggests that if a tunnel had been described, it would have been, as it was in one Thai account, part of the otherworld geography and not a feature of the journey there.

\section{Western New Britain}

Dorothy Counts (1983) reported three cases of NDEs among the Kaliai as part of her 1981 anthropological fieldwork. Once again, other realms were visited and deceased relations and friends were met. The afterlife environment, as in previous accounts, had a strong physical and social resemblance to the usual world of the experiencer. So far, we see these two features of the NDE, encountering other worlds and deceased beings, as steady, recurring features of NDEs. As we shall see in other non-Western cases, this trend will continue.

There are two points to note about these particular Melanesian cases. The first is the single report of a life review; the second is the 
absence of an OBE or tunnel experience. However, the picture is somewhat more complex than these first impressions may suggest. Although one person reported a life review, this respondent stated that he also witnessed a review of someone else's life, a sorcerer's. This review was narrated by the NDEr as a visit to a place where sorcerers are placed "on trial." Each person stood on a series of magnetic "manhole covers." If these held the person fast, so that others had to assist him in freeing himself, then he was called to account. If his explanation was unsatisfactory or unforthcoming, a series of punishing events occurred, ending with burning by fire. This is an unusual account, for as Counts noted, "there was no pre-contact notion of judgement of the dead for their sins" (1983, p. 129).

However, Counts noted that the Western New Britain area had been "missionized" by Catholicism since 1949. Many of the Kaliai were at least nominally Catholic, although traditional and Christian ideas often existed side by side. This may have accounted for the life review in this case. This was not the first case of mixed cultural imagery in an NDE. Pasricha and Stevenson (1986) reported an American follower of Sai Baba, an Indian holy man, who almost died in a hotel. His NDE featured the Indian life review of having his life record read by others.

Although no OBE was reported in the Kaliai NDE reports, one OBE was reported by Counts that may have been a vivid dream, hypnagogic imagery, or a nonNDE-related OBE (1983, p. 123). Its nature is difficult to discern in that account because no dead or sleeping body was observed, nor was a new body identified. An ability to see unusual sights and travel vast distances was connected with characteristics of the spirit world. The question of OBEs among the Kaliai, then, must be left open. There is a possibility that interpretations of similar experiences by Westerners may favor an OBE explanation, while those of the Kaliai may not.

Finally, in no case was a tunnel experience identified. All informants reported the early part of their NDE as walking on a road. However, in one case the NDE began in darkness, which gave way to a walk in a field of flowers. Only after this part of the experience did the walk continue onto a road (Counts 1983, p. 119).

\section{Maori New Zealand}

In an autobiographical exploration of New Zealand white culture and its encounter with the native Maori culture, Michael King (1985) 
recounted a Maori NDE. Nga was a Maori woman who encountered her first white person when she was "a girl just over school age" (King, 1985 , p. 92). A favorite story of Nga's was apparently one about the occasion when she believed she had died:

I became seriously ill for the only time in my life. I became so ill that my spirit actually passed out of my body. My family believed I was dead because my breathing stopped. They took me to the marae, laid out my body and began to call people for the tangi. Meanwhile, in my spirit, I had hovered over my head then left the room and traveled northwards, towards the Tail of the Fish. I passed over the Waikato River, across the Manukau, over Ngati Whatua, Ngapuhi, Te Rarawe and Te Aupouri until at last I came to Te Rerenga Wairua, the leaping off place of spirits. (King, 1985, pp. 93-94)

At this sacred place she performed the ablutions expected of the departed. Ascending to a ledge, she gazed down at the entrance to the underworld. After performing a dance, she prepared to descend into the subterranean passage leading to the realm of the spirits. At this point, she was stopped by a voice who told her that that her time had not come and that she must return until called again. She then returned to her body and awoke to see her anxious living relatives.

In this Maori account, no mention of a tunnel was made; instead, Nga flew to the land of the dead after her OBE (for example, "I had hovered over my head then left the room"). However, the story of Nga takes us to the entrance of a subterranean underworld, and this, had she traveled to it, may have constituted a tunnel experience. This subterranean passage was a common feature of some Pacific cultures (Panoff, 1968) and may mean, for the purpose of this review, that a tunnel experience cannot be excluded. If the experience had lasted longer, perhaps Nga would have descended to that underworld place through the traditional dark passage. So the absence of a tunnel sensation must be seen as a conditional matter that may have related idiosyncratically to this single account. Nevertheless, another characteristic, the life review, was unequivocally missing in this account.

\section{Native America}

Calvin Schorer (1985) reported two cases of NDEs from Native North Americans and more recently Jenny Wade (2003) described 11 cases. Shorer's accounts were identified from Henry Schoolcraft's (1825) nineteenth-century work Travels in the Central Portion of the 
Mississippi Valley. In these accounts, OBEs and encountering other realms and deceased beings were reported. The other realm, as in all previous cases, was similar to the former world of the experiencer. Absent from these two accounts were any references to a tunnel experience or a life review. Drawing from an assortment of early ethnographic and historical documents, Wade provided us with both a critical analysis of the earlier Schorer accounts and a nuanced and more reliable account of another 11 NDEs from six different Indian cultures in North America. She too observed the absence of descriptions of tunnel-like experience and life reviews. The emphasis in these stories appeared to be on walking journeys and the encountering of trials and tests, as well as meeting deceased friends and relatives in a supernatural environment.

Similar to the accounts from Guam and Western New Britain, experiencers emphasized their journey. The narratives were a series of tales about what happened to them after they discovered that they were dead. This pattern was repeated in the only account to appear from South America.

Juan Gómez-Jeria (1993) reported a single NDE account from the Mapuche people in Chile. Again, in that account, there was an absence of descriptions of a tunnel sensation or life review. The NDE reported here contained a visit to other worlds and the meeting of deceased beings.

\section{Aboriginal Australia}

An isolated account of an NDE among Australian aborigines has appeared in several ethnographies during this century. It was, by all accounts, an unusual story in aboriginal terms because it was not a mythical account that could be interpreted as part of the aboriginal "dream time." (For an excellent description of the aboriginal "afterlife" that is commonly interpreted as part of the aboriginal dreamtime, see the example provided by Ramsay Smith [1930, pp. 173-182].) However, the most interesting feature of the anomalous story I provide here, of which there are several versions, was that it was an historically real account of a human being who visited the land of the dead.

Lloyd Warner (1937) retold a version of the account as "Barnumbi and the Island of the Dead" in A Black Civilization. More recently, Ronald and Catherine Berndt (Berndt and Berndt, 1989) have reported the same story told to them as "Yawalngura dies twice?" 
According to the Berndts, "the story is now quite old and part of a long oral tradition" (Berndt and Berndt, 1989, p. 376).

The account was a long one, so I will summarize only the main elements. Yawalngura was out gathering turtle eggs with his two wives. He ate some of the eggs, after which he lay down and "died." Later, his wives returned from their own search and found him dead. They returned his body to the main camp and with others built a mortuary platform for him. After this, Yawalngura revived and told others that he became curious about the land of the dead. He decided to build a canoe so that he could travel there to visit. This he did and set off on a journey lasting for several days and nights. Finally, he arrived at an island where he met traditional spirits, such as the Turtle Man Spirit, and deceased beings who recognized that he was alive and had to return. These spirits then danced for Yawalngura and gave him gifts, such as a Morning Star emblem and yams for his return journey:

Yawalngura took those things which were given to him. All the spirit people danced at that special spring (well), and they told Yawalngura that he had to return: 'You have to return, you're not dead properly; you've still got bones. You can come back to us when you die properly." (Berndt and Berndt, 1989, p. 381)

Yawalngura returned and told others of his fantastic epic journey. "Two or three days afterwards," however, Yawalngura died again, "only this time he did so properly" (Berndt and Berndt, 1989, p. 381).

In this account, deceased beings and a land of the dead were visited. Again, both the people and the place had traditional mythical qualities. However, no tunnel experience and no life review were mentioned. Although the OBE is regarded as common in aboriginal Australia, especially during sleep and dreaming, no OBE was mentioned in this NDE account. These were also features of the final accounts from Africa.

\section{Africa}

Fifteen accounts of NDEs were described in Melvin Morse and Paul Perry's work Transformed by the Light (1992, pp. 120-126). These accounts came from informal correspondence from a medical colleague in Zambia. Although Morse and Perry labeled these accounts as emerging from "deepest Africa" (1992, p. 120), their cases were not entirely unambiguous in a cultural sense. That is, some of these cases may have been influenced by Western and local cultures. Nevertheless, I 
include them here because they appeared to be basically consistent with other NDE accounts from hunter-gatherer societies mentioned above.

Morse and Perry described accounts from a truck driver, a dentist, a clerk, and a charcoal burner, but other accounts were drawn from unknown occupations such as "a grandmother," "a widow," or "a child." Each of these accounts emerged from near-death experiences from illness or accident. The NDEs included walking journeys; some experiences of darkness; meeting deceased people, some of these in white robes; and supernatural beings, in one case "Jesus." One NDEr described being caught inside the hollow shell of a gourd from which she tried to extricate herself, eventually successfully.

Morse and Perry argued that these NDEs have all the basic features of Western NDEs, including even tunnels (1992, p. 124). However, a close scrutiny of their text and cases presented in the book revealed neither evidence nor words that described tunnels. They appeared simply to assume that the darkness experienced by two NDErs qualified as "tunnel" sensations. Furthermore, although Morse and Perry argued that the life review is a basic feature of NDEs, that feature was not presented in any of their 15 cases from Africa. There was also no report of an $\mathrm{OBE}$ in these cases.

\section{Summary and Discussion of Non-Western NDE Features}

Table 2 summarizes the preceding review of the non-Western NDE. It identifies features that seem crosscultural, those that appear to be culture-specific, and those in which the question of universality remains ambiguous.

In every case discussed, deceased or supernatural beings were encountered. These were often met in another realm, variously described as the "land of the dead," the "island of the dead," the "pure land," and so on. Consistently, the other realm was a social world not dissimilar to the one the experiencer was from, or in the case of many Asian accounts, not dissimilar from the one expected in the "underworld." The major difference was that this world was either often much more pleasant socially and physically, or much less appealing. Clearly, the consistency of these reports from highly diverse cultures suggests that at least these two features of the NDE are indeed crosscultural.

This distinction was less clear in the findings about the OBE. Some cultures, such as the New Zealand Maori, Native American, and Chammorro, clearly experienced some kind of OBE with their NDE. 


\section{Table 2}

Features of non-Western NDEs

Culture

Tunnel OBE Life Review Beings Other World

Asia:

China

India

Thailand

Tibet

Pacific Area:

Western New Britain

Hawaii

Guam

Maori

$\begin{array}{ll}? & + \\ - & + \\ ? & + \\ - & +\end{array}$

$\begin{array}{lll}+ & + & + \\ + & + & + \\ + & + & + \\ + & + & +\end{array}$

Hunter-Gatherer Societies:

Native America

Africa

Aborigine

$?$
$?$
-
$?$

$?$
+
+
+

$?$
-
-
-

$\begin{array}{ll}+ & + \\ + & + \\ + & + \\ + & +\end{array}$

$+=$ feature present

$-=$ feature absent

$?=$ feature questionable

However, the African NDE accounts did not report this feature. Finally, the sole Australian aboriginal account did not report an OBE, but OBEs are known in this culture. In fact, OBEs are known in the vast majority of cultures (Sheils, 1978) but these may not necessarily occur, or occur consistently, in NDEs in these cultures. The apparent randomness of the finding concerning OBEs makes conclusions about them in relation to the NDE ambiguous. On the basis of the present data, we are unable to judge whether these are crosscultural or culture-specific features.

However, clearer patterns emerge when the life reviews and tunnel experiences are examined in the different non-Western cases. NDErs from hunter-gatherer societies did not seem to report life reviews or tunnel experiences. There is no doubt that many experiencers reported an experience of darkness, which may be described as a "night" experience or as emerging from the darkness inside a vegetable, such as a gourd. This was similar to experiences described in Asian accounts where NDErs may describe emerging from a darkness inside the throat of a flower. Clearly in these cases, descriptions of experience cannot be 
separated from the language employed in the service of that description. Movement through darkness seemed to be described by the most culturally appropriate way for an individual and choice of words simply reflected this. Tunnels were common descriptors in the West because tunnels are widespread symbols and images in Western cultures and frequently occur in their landscapes, sciences, children's literature, and traditional legends and fantasy. But these are culture-bound images and experiences. There is no actual "tunnel" in near-death experiences: the darkness frequently associated with NDEs may be described differently by different cultures.

Life reviews seemed also to be an absent element in NDEs from hunter-gatherer societies. Robert Bellah (1976) argued that the psychology of conscience is associated with religions that place moral emphasis on personal responsibility for moral conduct. Religions such as Judaism, Christianity, Buddhism, or Hinduism emphasize personal ethics as opposed to group or tribal responsibility. Small-scale societies such as hunter-gatherer ones tend to emphasize the group's relationship to totemic beliefs, symbols and storylines that link an individual's moral journey in life to that of his family and tribe (Roheim, 1932). In that kind of society, autobiographical reflection and individual life review are less valuable and practical than an understanding of the group's place in the cosmological order of time. If this view has any anthropological currency, we should be unsurprised by the absence of personal life reviews in old hunter-gatherer accounts of NDEs.

Overall, then, the present review has revealed that the major crosscultural features of the NDE continue to appear to include encountering other beings and other realms on the brink of death. Life reviews and tunnel experiences seem to be culture-specific features. Life reviews seemed to be a feature of Western, Chinese, and Indian NDE accounts. Cases collected from hunter-gatherer, primitive cultivator, and herdsmen societies did not exhibit this feature. The tunnel experience was not described in most non-Western accounts, though an experience of darkness of sorts was often reported. The present review has revealed no major pattern in reports about the OBE in non-Western NDE accounts, and therefore this finding must be viewed as inconclusive.

\section{References}

Bailey, L. W. (2001). A "little death": The near-death experience and Tibetan delogs. Journal of Near-Death Studies, 19, 139-159. 
Becker, C. (1981). The centrality of near-death experiences in Chinese Pure Land Buddhism. Anabiosis: The Journal of Near-Death Studies, 1, 154-171.

Becker, C. (1984). The Pure Land revisited: Sino-Japanese meditations and near-death experiences of the next world. Anabiosis: The Journal of Near-Death Studies, 4, 51-68.

Bellah, R. N. (1976). Beyond belief: Essays on religion in a post-traditional world. New York, NY: Harper and Row.

Berndt, R. M., and Berndt, C. H. (1989). The speaking land: Myth and story in Aboriginal Australia. Harmondsworth, England: Penguin.

Blackmore, S. J. (1993). Near-death experiences in India: They have tunnels, too. Journal of Near-Death Studies, 11, 205-217.

Blackmore, S. J., and Troscianko, T. S. (1989). The physiology of the tunnel. Journal of Near-Death Studies, 8, 15-28.

Counts, D. A. (1983). Near-death and out-of-body experiences in a Melanesian Society. Anabiosis: The Journal of Near-Death Studies, 3, 115-135.

Douglas, M. (1966). Purity and danger. London, England: Routledge and Kegan Paul.

Gómez-Jeria, J. S. (1993). A near-death experience among the Mapuche people. Journal of Near-Death Studies, 11, 219-222.

Green, J. T. (1984). Near-death experiences in a Chammorro culture. Vital Signs, 4(1-2), 6-7.

Kellehear, A. (1993). Culture, biology, and the near-death experience. A reappraisal. Journal of Nervous and Mental Disease, 181, 48-56.

Kellehear, A. (1996). Experiences near death: Beyond medicine and religion. New York, NY: Oxford University Press.

Kellehear, A. (2001). An Hawaiian near-death experience. Journal of Near-Death Studies, 20, 31-35.

Kellehear, A. (In press). Census of non-Western near-death experiences to 2005: Observations and critical reflections. In J. M. Holden, B. Greyson, and D. James (eds.), Handbook of Near-Death Experiences: Thirty Years of Research. Westport, CT: Greenwood/Praeger.

Kellehear, A., Heaven, P., and Gao, J. (1990). Community attitudes toward near-death experiences: A Chinese study. Journal of Near-Death Studies, 8, 163-173.

Kellehear, A., Stevenson, I., Pasricha, S., and Cook, E. (1994). The absence of tunnel sensation in near-death experiences from India. Journal of Near-Death Studies, 13, 109-113.

King, M. (1985). Being Pakeha: An encounter with New Zealand and the Maori Renaissance. Auckland, NZ: Hodder and Stoughton.

Lai, W. (1996). Tales of rebirths and the later Pure Land Tradition in China. In J. Foard, M. Solomon, and R. K. Payne (eds.), The Pure Land tradition: History and development (Berkeley Buddhist Studies, Series 3). Berkeley, CA: Institute of Buddhist Studies.

Morse, M., and Perry, P. (1992). Transformed by the light: The powerful effects of neardeath experiences on people's lives. New York, NY: Villard.

Murphy, T. (2001). Near-death experiences in Thailand. Journal of Near-Death Studies, $19,161-178$.

Ogasawara, S. (1963). Chugoku kinsei jodokyoshi no kenkyu [Research on the history of Pure Land Buddhism in recent China]. Kyoto, Japan: Hyakkaen.

Osis, K, and Haraldsson, E. (1977). At the hour of death. New York, NY: Avon.

Panoff, M. (1968). The notion of the double self among the Maenge. Journal of the Polynesian Society, 77, 275-295.

Pasricha, S. (1992). Near-death experiences in South India: A systematic survey in Channapatna. National Institute of Mental Health and Neuro Sciences Journal, 10, 111-118.

Pasricha, S. (1993). A systematic survey of near-death experiences in South India. Journal of Scientific Exploration, 7, 161-171. 
Pasricha, S., and Stevenson, I. (1986). Near-death experiences in India: A preliminary report. Journal of Nervous and Mental Disease, 174, 165-170.

Pommaret, F. (1989). Les revenants de l'au-delà dans le monde tibétain: Sources littéraires et tradition vivante [Those who return from the hereafter in the Tibetan world: Literary sources and living tradition]. Paris, France: Editions du Centre National de le Recherche Scientifique.

Roheim, G. (1932). Psychoanalysis of primitive cultural types. International Journal of Psychoanalysis, 13, 1-224.

Schoolcraft, H. R. (1825). Travels in the central portion of the Mississippi Valley. New York, NY: Collins and Henry.

Schorer, C. E. (1985). Two Native North American near-death experiences. Omega, 16, 111-113.

Sheils, D. (1978). A cross-cultural study of beliefs in out-of-body experiences, waking and sleeping. Journal of the Society of Psychical Research, 49, 697-741.

Smith, W. R. (1930). Myths and legends of the Australian aboriginals. London, England: George G. Harrap and Company.

Thrum, T. (1907). Hawaiian folk tales: A collection of native legends. Chicago, IL: A. C. McClurg.

Wade, J. (2003). In a sacred manner we died: Native American near-death experiences. Journal of Near-Death Studies, 22, 82-114.

Warner, W. L. (1937). A black civilization: A social study of an Australian tribe. New York, NY: Harper and Brothers.

Woerlee, G. M. (2004). Cardiac arrest and near-death experiences. Journal of NearDeath Studies, 22, 235-249.

Zhi-ying, F., and Jian-xun, L. (1992). Near-death experiences among survivors of the 1976 Tangshan earthquake. Journal of Near-Death Studies, 11, 39-48. 